\title{
Contexto de la actividad y el pensamiento de Mary Richmond
}

\author{
Montext of the activity and thought of Mary Richmond \\ Miguel Miranda ARANDA \\ Facultad de Ciencias Sociales y del Trabajo[Universidad de Zaragoza \\ mmiranda@unizar.es
}

Recibido: 05/04/2011

Revisado: 05/04/2011

Aceptado: 09/06/2011

Disponible on line: 29/09/2011

\begin{abstract}
Resumen
Para entender la importancia de cualquier personaje y de su obra, resulta imprescindible situarlo apropiadamente en el contexto social y científico. Mary Richmond es una de las pioneras de una nueva profesión que nace a la vez que las Ciencias Sociales, autora clave en la configuración de una disciplina a partir de su propia investigación y de las influencias que recibió de otras profesiones más consolidadas y de las principales escuelas de pensamiento del momento, en concreto de la Filosofía pragmatista de James y Dewey, de las incipientes teorías formuladas en el Departamento de Sociología y Antropología de la Universidad de Chicago entre las que se incluyen de manera sustancial los enfoques interaccionistas de George Herbert Mead. Todo ello en una coyuntura de cambios económicos, sociales y políticos, durante los años de la denominada era progresista de los EE.UU.
\end{abstract}

Palabras clave: Trabajo Social, pioneras, pragmatismo, interaccionismo simbólico.

\begin{abstract}
In order to understand the significance of an author and his or her work, it is essential to appropriately consider the author's social and scientific context. Mary Richmond was one of the pioneers in a new profession that emerged at the same time as the Social Sciences. She was key in the shaping of the discipline thanks both to her own research and the influence that other more established professions and major schools of thought of the time had on her work, specifically James' and Dewey's Pragmatic Philosophy and the theories emerging from the University of Chicago's Departments of Sociology and Anthropology, among them including most substantially the interactionist approaches of George Herbert Mead. All of this in an environment of economic, social and political change during the Progressive Era in the United States.
\end{abstract}

Keywords: Social Work, pioneers, pragmatism, symbolic interactionism.

Referencia normalizada: Miranda Aranda, M. (2011). «Contexto de la actividad y el pensamiento de Mary Richmond». Cuadernos de Trabajo Social, 24: 35-45.

Sumario: Introducción. 1. El contexto social e intelectual a finales del siglo XIX. 1.1. El contexto social. 1.2. El contexto intelectual. 1.2.1. Pragmatismo. 1.2.2. Individuo-sociedad. 2. Referencias bibliográficas.

\section{Introducción}

Qué duda cabe de la importancia de entender el contexto social, político e intelectual en el que vive y, por tanto, en el que se desarrolla la obra de cualquier personaje. Parece claro que sin tal reflexión no es posible conocer ni valorar con justicia las decisiones de un político, los descubrimientos de un investigador, o las aportaciones a tal o cual disciplina de sus pioneros. La pretensión de juzgar desde nuestra época el pasado y hacerlo conforme a nuestros valores y a nuestros conocimientos actuales es sin duda frecuente, pero poco rigurosa. A cada autor hay que situarlo en su contexto. Todavía más, hay muchos que piensan, con razón, que sin tal contexto no hay au- 
tor y que de alguna forma el avance científico es en cierta manera colectivo aunque se personalice, que el descubrimiento sólo emerge concatenado a episodios anteriores y en determinado caldo de cultivo que lo hace posible. Partir de esta posición nos ayudará a entender mejor la figura a la que dedicamos estas páginas, una de las pioneras del Trabajo Social, profesional destacada, profesora y formuladora de teoría que propuso la primera declaración exhaustiva, de gran alcance, de los principios de la práctica directa del Trabajo Social, según le reconoce la Enciclopedia de la NASW $(1995,2005)$. Sólo atendiendo a esta declaración de méritos, efectuada por fuente tan fiable, merecería la atención de cuantos tenemos relación profesional o disciplinar con el Trabajo Social. En unos casos para conocerla porque sigue siendo en gran parte desconocida, con algunos de sus libros sin traducir al castellano todavía. En otros, para reivindicar su figura, aunque sólo sea porque merece estar con todos los honores y sin ninguna duda, incluida en el grupo de mujeres que «inventaron» el Trabajo Social. De la misma manera al menos que cualquier sociólogo, psicólogo, antropólogo o cualquier otro practicante de una ciencia o disciplina científica reconoce y estudia a sus «ancestros» independientemente del grado de acuerdo que personalmente tenga con las teorías propuestas por el antepasado en cuestión. No conozco a ningún psiquiatra que se identifique con Kraepelin, pero todos reconocen sus esfuerzos. Ningún sociólogo defiende en su integridad la obra de Spencer o de Comte, o de Durkheim o de Marx, pero tampoco conozco a ninguno que niegue lo que supuso cada uno de ellos en la construcción disciplinar. Conozco psicólogos conductistas que se tomaron la molestia de estudiar a Freud a Rank, a Erikson o a Lacan y a psicoanalistas que conocen perfectamente las aportaciones de Watson, de Skinner o de Paulov. Ninguno de ellos les negará su papel y sus aportaciones, aunque esté lejos de compartirlas. Cualquier filósofo que se precie, y habrá que reconocer la larga trayectoria de su disciplina, conoce la filosofía griega, la escuela jónica y Heráclito, la pitagórica, a Parménides, a los sofistas y por supuesto a Sócrates, Aristóteles o Platón; seguro que tiene alguna idea de la Esco- lástica y ya no digo nada de las Escuelas y autores modernos y contemporáneos porque una Escuela sucede a la anterior y se explica desde la anterior proponiendo nuevos enfoques, nuevos problemas y soluciones. Podía seguir enumerando disciplinas, incluida la Antropología, en la que me licencié y doctoré, pero espero haber convencido al lector sin necesidad de más insistencia.

Con Mary Richmond, y en general con todo lo que tiene que ver con Inglaterra y Estados Unidos, sucede en el medio hispano algo curioso. En España, durante las generaciones de le transición y posteriores al franquismo se la conocía exclusivamente por el texto traducido por Humanitas con el título de «Caso social individual». Del Social Diagnosis, en general, sólo se tuvo noticia mucho después, por aquellos tres capítulos traducidos en la edición de Talasa prologada por Mario Gaviria y más recientemente por la traducción de Siglo XXI. Es decir, el conocimiento de su obra y de su figura era limitada en cualquier caso. Sin duda, en ausencia de otros textos que estudiar, el editado por Humanitas fue muchas veces utilizado como manual, aunque se desconociera en gran parte precisamente el contexto intelectual en el que había que interpretarlo. En cualquier caso, los aires reconceptualizadores procedentes de Latinoamérica, que nos impregnaron a todos en los setenta, acabaron estigmatizando por asistencialista y funcionalista no ya a Mary Richmond y a las COS, sino a todo el Trabajo Social que se expresaba en inglés por lo que nuestra pionera acabó siendo considerada como algo prescindible y digno de olvidar. $\mathrm{Pa}-$ ra ello se olvidó quien «inventó» esta profesión, dónde y para qué nació y quienes fueron los protagonistas de sus primeros pasos, en qué se apoyaron, cuáles fueron las fuentes teóricas en las que saciaron su sed de conocimientos... Todo ello carecía de interés. El esfuerzo había que ponerlo en construir la profesión y sobre todo el ámbito profesional, el sistema de servicios en el que ejercer en el interior de cada país, como si fuese posible un proceso singular y autónomo que nada tuviera que ver con lo que pasaba más allá de las fronteras de cada Estado. No conozco otras disciplinas con voluntad de ser científicas, donde se hayan dado intentos parecidos. 
Quiero pensar que, por lo que se refiere a España, el desarrollo del Trabajo Social en el ámbito académico ha paliado la situación anterior al menos en parte. Creo que todavía queda mucho por descubrir y conocer de nuestra propia historia. Afirmo también que las nuevas generaciones no comparten aquel estigma al que me refería anteriormente y se acercan sin prejuicios a Mary Richmond, a Jane Addams o a otras pioneras de aquella generación o de las posteriores, por mucho que vivieran en Nueva York o en Chicago. La situación en muchos países latinoamericanos es sin duda diferente. Como allí y aquí en los setenta, el estigma sigue estando en vigor y hablar y defender a aquellas mujeres atrae sobre quien lo haga la etiqueta de neoliberal. Yo puedo entender, cómo no, posiciones políticas enfrentadas a las que han desarrollado en Latinoamérica gobiernos norteamericanos republicanos o demócratas. Comparto de hecho la condena radical de muchos colegas al neoliberalismo. Ahora bien, confundir la Escuela de Chicago con los "Chicago boys» sólo lo puedo entender afirmando la total ignorancia de quien cae en semejante error. Y fue en público, en un Congreso profesional celebrado en Villa Gesell, ante más de trescientos colegas, el lugar en el que todo un licenciado en Trabajo Social por la Universidad de La Plata, intentó discutir conmigo de la cuestión, sin haber oído hablar en su vida de Dewey, de Park, de Thomas, de las monografías de Chicago, de Mead y el Interaccionismo simbólico, o de nuestra premio Nobel de la Paz Jane Addams. Lo significativo es que días después me escribió un mensaje ratificándose en su error a partir de lo que había descubierto en Google y en la wikipedia. Algunas de sus profesoras, de la misma Universidad presentes en la mesa, lejos de llamar a la prudencia a su ex-alumno trataron de desviar la cuestión seguramente para no tener que reconocer la ignorancia compartida. Cuento este episodio lamentable y triste porque es significativo. Hay una tendencia poderosa en Latinoamérica formada en determinadas universidades, por tanto alimentada por académicos que, en muchos casos, no han ejercido la profesión nunca (a veces ni es la suya), pero que sin ningún pudor ni respeto pontifican sobre lo que ésta debe de ser y hacer, acudiendo a estas alturas nada menos que a Rosa Luxemburgo por ejemplo $^{1}$. La consecuencia es la desorientación y una falta de identidad impropia después de más de cien años de trayectoria (Butrym, 1976). Con un empeño militante digno de mejor causa prescinden de quienes configuraron el Trabajo Social y, lo que es más grave, sin conocerlas. Todo es asistencialismo, funcionalismo de la peor especie, colonialismo, imperialismo, iyo qué sé! Y cuando se pretende defender a aquellas mujeres corres el riesgo de que te coloquen los mismos ismos sin ningún pudor. $\mathrm{Y}$ en el camino, generaciones enteras de trabajadores sociales desconocen cómo, dónde y por qué nació el Trabajo Social de Grupo o la intervención colectiva, quién era aquella mujer singular que fundó Hull House y que luego fue Premio Nobel de la Paz. Y nunca han reflexionado, porque no la han leído siquiera, sobre qué quería decir Mary Richmond cuando reclamaba la intervención «al por menor» y «al por mayor» o cuando afirmaba que la limosna «es hasta tal punto antidemocrática que la reprobación le llega tanto al que la da como al que la recibe y constituye una maldición para ambos. La ayuda, en sí y por sí, no tiene ninguna calidad moral y menos que cualquier otra la de poder tornarse democrática», afirmación que hacía en el libro traducido por Humanitas, titulado "Caso Social individual», o a qué cuento venía aquella afirmación tan rotunda respecto a que «la democracia no es una forma de organización; es un hábito cotidiano» (1982, p. 166). ¿Cuáles eran los dilemas a los que tuvieron que dar respuestas?, ¿de qué corrientes teóricas se alimentaron aquellas mujeres?, ¿cuáles eran las imperantes en el momento que les tocó vivir?, ¿se alinearon con los evolucionistas o contra ellos? (Walkowitz, 1999).

${ }^{1}$ Me refiero a lo sucedido en un Congreso de estudiantes de Trabajo Social celebrado el año pasado en Mendoza, (Argentina) y a cuya acto/mitin final he accedido gracias a Internet. Por otro lado, la falta de respeto que denuncio no es menos frecuente en España, lamentablemente, ante la pasividad, cuando no complacencia o complicidad, de parte del colectivo profesional e incluso académico. 
Es verdad también que no pocas universidades en Argentina, en Chile y en otros muchos países se están alejando desde hace años de esas posiciones, intentando construir otras identidades desde la historia profesional, lo que significa ni más ni menos que un compromiso con los derechos humanos, con una serie de valores como la justicia y la igualdad, la esencial dignidad de cualquier ser humano... presentes no sólo en los textos que dejaron escritos, sino en su compromiso profesional y vital. También en España y en Portugal parece haber surgido el interés por las pioneras y la importancia de conocerlas y rehabilitar su memoria, tan injustamente despreciada por prescindible en las aguas agitadas de la transición a la democracia. La tarea es, por tanto, facilitar su conocimiento y en eso estamos.

\section{El contexto social e intelectual a finales del siglo XIX}

\subsection{El contexto social}

Si hacemos caso a la propia Mary Richmond en la última década del siglo XIX ya había profesionales del Trabajo Social. No fueron otras que aquellas voluntarias que en el seno de las COS acabaron siendo expertas gracias a la experiencia adquirida sobre el terreno, complementada con la formación en la propia organización y, en ocasiones, algún tipo de formación académica o que se convirtieron en profesoras. Pero en el Trabajo Social, como en las Ciencias Sociales en general, las primeras décadas del XX fueron cruciales para su desarrollo y construcción identitaria (Leighninger, 1987; Butrym, 1976).

Hay autores como Birbaum (2001) o Maldwyn A. Jones (1995, p. 341) que se refieren a esta época como «la era progresista». Una era en la que se produce, según expresión de este último, una vigorosa ola de reforma que barrió los Estados Unidos entre 1900 y 1917 , y que se caracterizó por la amplitud de sus preocupaciones que incluían: la regulación de la economía por parte del Gobierno, la purificación de la política, la reducción de los aranceles, la prohibición de fabricar y vender bebidas alcohólicas, el sufragio femenino, la reforma municipal, la mejora de las condiciones, el trabajo infantil, la vivienda y la salud pública, el trata- miento de la pobreza, el vicio y el delito, y la conservación de los recursos naturales. Se trata de una reflexión de ámbito nacional que tiene como escenario sobre todo las ciudades y que se realiza en una época de prosperidad. El pensamiento progresista, dice Jones, se expresaba como grupos de presión dentro de los dos partidos políticos, demócratas y republicanos y presentaba cierta complejidad. No era un movimiento unificado sino un conglomerado de impulsos reformistas a veces divergente y contradictorio. «No obstante, existía un tipo de mentalidad que podía reconocerse como progresista y que unía a reformistas tan diferentes como el editor de Kansas, Willian Allen White, la trabajadora social de Chicago, Jane Addams, el publicista Frederic C Howe, el sociólogo Edward A. Ross, el filósofo John Dewey y, hasta cierto punto, a políticos como Theodore Roosevelt y Robert M. Lafollete.»

Resulta ya curioso y digno de hacer notar que en esta breve enumeración el historiador cite a Dewey y a Jane Addams entre los progresistas más reconocidos. Dos figuras relevantes en los inicios del Trabajo Social. El primero, por su influencia filosófica en la Escuela de Chicago, y la segunda, por ser ella misma una de las pioneras más conocidas y reconocidas. La «santa Jane», le llamaban (Elshtain, 2002). Después pasaría a ser por su discurso pacifista, la mujer más peligrosa de los EE.UU., según el FBI. Sin duda, Mary Richmond no gozó del nivel de popularidad de la fundadora, y directora hasta su muerte, de Hull House, pero no por ello se puede decir que los objetivos de ambas estaban muy alejados. Los objetivos de los settlement houses, su manera de trabajar sobre el terreno, su vinculación a la universidad de Chicago (Deegan, 1990), su especial relación con la vida política, el grupo de hombres y mujeres notables que coincidieron en Hull House... contribuyeron sin duda a que Jane Addams fuese más conocida que Mary Richmond y las COS centradas en una construcción metodológica que pone su atención en el individuo, aunque nunca renunciaran a lo que se llamaba la reforma social. La líder de las COS saluda con entusiasmo el nacimiento de esta nueva rama del Trabajo Social, que es el que representa Jane Addams y su movimiento con el que 
siempre buscó la complementariedad, sin ninguna pretensión de exclusión ${ }^{2}$. Mary Richmond se dedicó a formular los principios y métodos del Trabajo Social de casos individuales, pero conviene no olvidar que en su obra de madurez dedica un capítulo a «Las diversas ramas del Servicio Social y sus relaciones recíprocas». En este capítulo dice:

Las otras ramas del servicio social que están todas en relación recíproca con el servicio social de casos individuales son tres: tienen por objeto los servicios sociales colectivos, las reformas sociales y las investigaciones sociales. El servicio social de casos individuales se ocupa de establecer mejores relaciones sociales, tratando los individuos uno por uno en el círculo íntimo de la familia, pero el servicio social alcanza también los mismos fines generales por otros medios. Engloba una variedad considerable de operaciones que se ocupan de grupos -centros sociales (en la nota a pie de página aclara que está hablando de los settlement), obras de recreo, círculos, obras de barrio, obras locales-operaciones en las cuales el individuo, aunque se dirijan directamente a él, no es más que una unidad en un conjunto. Por un método diferente de aquellos que emplea el servicio social de casos individuales y los servicios sociales colectivos, y persiguiendo el mismo fin, el servicio de reformas sociales tiende a elevar «en conjunto» las condiciones en las cuales viven las masas, principalmente por la propaganda social y por la legislación social. Aunque el objetivo inmediato sea el de tratar el mejoramiento de la vivienda, de la salud, de las condiciones de trabajo, del empleo de los recreos o de numerosos otros fines perseguidos por las reformas sociales, el fin principal de éstas no por eso deja de ser el de hacer progresar la especie humana tornando mejores las relaciones sociales (1982, p. 148).

En el citado capítulo trata de demostrar «la dependencia del servicio social de casos individuales frente a otras ramas del servicio social y viceversa». Así, pues, creemos que se puede afirmar que la autora del Diagnóstico social participa del mismo movimiento progresista y persigue los mismos fines que la famosa directora de Hull House, aunque no fuera tan conocida como ella a nivel nacional.
$\mathrm{Su}$ formación y experiencia provenía de las COS y, por tanto, su investigación y su práctica estaba especializada en el enfoque individual, pero tenía perfecta conciencia de que en este nivel de intervención, por más que fuera imprescindible, (por cierto, como también lo pensaron antes que ella los socialistas fabianos), no se agotaba el Trabajo Social. Por el contrario, concibió ese nivel de intervención sólo como una parte de la profesión que ella contribuyó a nacer y a crecer, y compartiendo los mismos valores que otros colegas, desde otras experiencias, estaban proclamando. Es obvio, y conviene no olvidarlo, que en una trayectoria de décadas, las organizaciones y las personas evolucionan y cambian.

Desde que nacen las COS en Inglaterra y se extienden por los EE.UU. hasta 1922, fecha en que Mary Richmond publica ¿Qué es el servicio social de caso? han cambiado muchas cosas. Son décadas de cambios profundos en lo político, en lo económico y en lo cultural e intelectual. Son los años clave en el nacimiento de las Ciencias Sociales y se nota. Cuando nuestra pionera se pone a escribir Social Diagnosis en 1905, la principal Escuela de pensamiento social que va a ser la de Chicago, está dando sus primeros pasos. Casi veinte años después la influencia de Mead, de Park, de Thomas... está presente en el pensamiento de Mary Richmond. Ella estaba pendiente de lo que proponían los médicos, los abogados y, desde luego, los nuevos científicos sociales, (nos referiremos a estas influencias más adelante). Por tanto es indudable que ella evolucionó con su tiempo, como lo hicieron las COS y como lo hicieron los Settlement desde su nacimiento en Londres con los Barnett. Los dos movimientos eran amplios y, por tanto, complejos y, desde luego, no uniformes. Algunas actitudes propias del viejo calvinismo europeo eran identificables en las prácticas cotidianas de algunas organizaciones asociadas e incluso posiciones evolucionistas o incisivamente moralistas. $\mathrm{Ni}$ Jane Adams ni Mary Richmond las hubieran tolerado nunca a su alrededor. Ellas, al menos en su madurez, formaron parte de un mo-

2 «El conjunto del servicio social es mayor que cualquiera de las partes que lo componen» significa que incluye en la nueva profesión a la otra organización, los settlement, con la que no compartía los mismos enfoques pero con la que no competían desde las COS (Richmond, 1982, p. 173). 
vimiento reformista en el que hay que encuadrar el nacimiento de una profesión, que nació en el interior de las Ciencias Sociales con vocación de ser una disciplina aplicada, que se enfrentará a los efectos indeseados de la Revolución Industrial, que trabajará para que el bienestar social alcanzará a toda la población, independientemente del color de la piel, de la procedencia étnica o de ser hombre o mujer. Aquellas generaciones pioneras de trabajadoras sociales se comprometieron en todas aquellas cuestiones que de la mano del historiador Jones definían los anhelos del movimiento progresista, y en alguna más como la organización de los consumidores ${ }^{3}$. Ese y no otro, es el contexto y el origen del Trabajo Social.

El nacimiento del Trabajo Social está relacionado íntimamente con el nacimiento de las Ciencias Sociales en general y dentro de ellas nace con una vocación clara: ser una disciplina aplicada, nace para producir cambios, para intervenir en la realidad social. En realidad, afirma Menand (2002, p. 309) todas las ciencias sociales americanas en esencia se constituyeron en disciplina como una reacción contra las ideas de laissez-faire asociadas con Sumner y con su profesor de filosofía, Herbert Spencer. Su nacimiento tiene que ver con el intento de poner orden en el caos reinante, consecuencia de la industrialización en las condiciones impuestas por el capitalismo liberal y salvaje, pero tiene que ver también con la secularización de la sociedad y, por tanto, con el abandono de las explicaciones proporcionadas por la moral y la religión y la confianza en la ciencia para orientar el cambio. Lo que hacen tanto Jane Addams como Mary Richmond es investigar (Plummer, 1997, p. 8; Richmond, 2005). La primera investigación sobre lo que sucede en los barrios de las ciudades y la segunda sobre lo que hacían las trabajadoras sociales en sus intervenciones. En los dos casos, investigar para fundamentar la intervención fuese colectiva o individualizada. Son los métodos científicos y no las ideas religiosas las que proporcionan los fundamentos, aunque se compartan determinados valores y maneras de concebir al ser humano y a la sociedad.

La profesión de Trabajo Social, fue forjada en un momento de pleno cambio, fue el sello del siglo XIX. A principios de siglo, los americanos tenían una visión del mundo por la cual veían a dios y a la religión como el motivo y la causa de la mayoría de los acontecimientos de la vida. Gradualmente esta perspectiva cambió, y hacia finales de siglo los americanos tenían una perspectiva más secular y humanística. La religión era todavía importante pero la creencia de que la sociedad podía ser configurada e incluso mejorada a través de los descubrimientos de la ciencia y la tecnología era generalmente aceptada. La emergencia del Trabajo Social es una pieza de esta historia (Dan Huff, cit. en Miranda, 2004, p. 109).

\subsection{El contexto intelectual}

Hellen Harris Perlman ${ }^{4}$ (1980), una trabajadora social de segunda generación y buena conocedora de la obra de Richmond, nos la describe como una mujer atenta a lo que se puede aprender de otras disciplinas, en concreto dice ella, del Derecho y de la Medicina. Si examinamos detenidamente las referencias bibliográficas que hace Richmond en sus obras confirmaremos que se trataba de una mujer intelectual al tanto de la producción científica en disciplinas dispares. Entre dichas referencias veremos cómo cita a Park y a Burgess y desde luego a George Herbert Mead, del que fue alumna y amiga y a quien concede una im-

3 Jones afirma: «la famosa Jane Addams fundó el primer campo de juegos público en Chicago en 1893 y después se concertó con Jacob Riis y otros en una campaña nacional en petición de campos de juegos públicos y pequeños parques. En 1915 ya más de 400 ciudades los habían establecido. También se desarrolló una perspectiva nueva y más compasiva de la delincuencia juvenil. Una de sus defensoras más destacadas fue Julia C. Lathrop, también de Hull House (...). Mientras tanto, una tercera trabajadora social de Hull House, Florence Kelley, se había puesto a la cabeza de un movimiento que pretendía abolir el trabajo infantil.» (Jones, 1995, p. 348). Para muestra valen tres botones.

${ }^{4}$ La primera edición del libro de Perlman es de 1960 y se tituló simplemente Social Casework. En él intenta unificar en un solo modelo las propuestas de lo psicosocial de la Escuela de Nueva York y las del modelo funcional propuesto por V. Robison y Taft en Pennsylvania. Los tres modelos fueron elaborados en el marco conceptual del psicoanálisis. 
portancia fundamental en el proceso de formación del Trabajo Social, cuando afirma que sus teorías constituyen la piedra angular del servicio social de casos individualizados. Seguramente esta afirmación me pasó desapercibida durante años. Sólo cuando a través de la Antropología estudié a Mead y el Interaccionismo simbólico fui consciente de las implicaciones de semejante afirmación. Cuando en un arco quitamos la piedra angular, el arco se hunde. Por tanto, a juicio de nuestra autora, no estamos hablando de algo periférico o baladí. Era necesario tirar del hilo e investigar el significado y el origen de teorías tan importantes. Y tirando del hilo llegamos a la Escuela de Chicago, la principal escuela de pensamiento social durante las primeras décadas del siglo XX en los Estados Unidos. En su interior nacen el primer manual de Sociología, la primera revista, la Asociación Americana de Sociología y se desarrollan teorías como la Ecología Humana y el Interaccionismo simbólico (Plummer, 1997) principales productos que orientan la producción de las famosas monografías de Chicago que en conjunto constituyen todavía hoy el intento más serio de estudiar una ciudad desde las Ciencias Sociales, además de ser el inicio de los modernos estudios urbanos (Hannerz, 1993). Chicago se había convertido en el laboratorio ideal para los científicos sociales. Era el paradigma de lo que supone un proceso de rápida urbanización en las condiciones impuestas por el capitalismo liberal, una ciudad que se industrializa y multiplica sus habitantes atrayendo a inmigrantes procedentes de los lugares más diversos (Miller, 1996). Y los sociólogos-antropólogos de la Universidad de Chicago no perdieron la ocasión. Y sobre el mismo escenario urbano se produjo el encuentro con las trabajadoras sociales. Hay quien, como Deegan, mantienen que incluso fue Addams la auténtica líder de dicha Escuela, aunque no fuera profesora universitaria. Eso sí, llevando el agua a su molino, la califica de socióloga puesto que había hecho investigación. Lo que es indiscutible es que sin las trabajadoras sociales, la Escuela de Chicago no hubiera significado lo que hoy significa en la historia de las Ciencias Sociales.

Naturalmente que, siendo el centro intelectual más reconocido del país hasta los años treinta, ejerció una gran influencia en los primeros pasos del Trabajo Social. A través de sus autores llegó la filosofía pragmatista y de la mano del Interaccionismo simbólico, el Trabajo Social encontró solución a algunos problemas teóricos que arrastraba. Más allá de la filosofía especulativa que teorizaba sobre las bases de la sociedad humana, y el progreso social que planteaba Small, las aportaciones de Thomas primero y de Park después suponen el intento de investigar los rasgos indeseables de la sociedad industrial al principio con pocas herramientas, con un entramado conceptual débil pero con la convicción de que el camino era la investigación empírica. Thomas marcó distancias con el biologicismo, fue pionero en el uso de «documentos personales» como diarios, cartas y autobiografías, relatos de experiencias, historias sociales y psiquiátricas, subrayó la necesidad de entender el punto de vista del actor, la «definición de la situación», junto con Znaniecki realizó un gran estudio sobre los inmigrantes polacos que constituye un hito de la Sociología americana. En fin, legó un conjunto de ideas importantes tales como la preocupación por el decrecimiento de la influencia de las reglas sociales de comportamiento existentes sobre los miembros de un grupo en el escenario de la gran urbe, donde con el anonimato, todo es posible. Park, por su parte, pasó del periodismo de investigación y de su militancia antirracista a ser el gran investigador de la ciudad, movido por parecidas preocupaciones que Thomas. Estudió las características de los barrios, las instituciones y la organización política, y teorizó sobre la superficialidad de las relaciones entre los individuos en la gran ciudad, sobre las «regiones morales» y los procesos culturales urbanos. Descubrir esos mundos sociales o regiones morales se convirtió en el objetivo de la ecología humana.

Hay quien mantiene que una de las razones de que la influencia de la Escuela de Chicago decayese fue precisamente la elección como objeto de estudio de los efectos indeseados de la industrialización, su interés por poner de manifiesto la peor cara de las ciudades norteamericanas, por descubrir y poner en evidencia aquellos aspectos incómodos para el poder. Su permanente reclamo de la democracia como instrumento de cambio social e 
incluso el compromiso político de sus líderes no era bien visto desde el poder. En este contexto, cuando precisamente el Trabajo Social daba sus primeros pasos y por tanto estaba ávido de teorías que le ayudasen a acercarse a la realidad desde la Ciencia, es fácil de entender que la relación y las mutuas influencias fueron intensas y fructíferas. E1 Trabajo Social nace precisamente con la vocación de ser una disciplina aplicada y no otra cosa, quiere producir cambios, intervenir en la realidad social. Para ello necesita investigar, aplicar el método científico. Ya no basta con la caridad o la filantropía. Las consecuencias de la revolución industrial y el proceso de urbanización imponen el uso de nuevos enfoques, de nuevos métodos, del máximo rigor en la explicación de la realidad y en los procesos de intervención. Para ello, necesita mantenerse en diálogo permanente con las Ciencias Sociales. Esta es una tarea a la que Mary Richmond invita y compromete a su generación y a las siguientes.

Desde ese diálogo el Trabajo Social se aprovecha de la importancia concedida al enfoque microsocial, no sólo a las grandes encuestas. Coincide en el estudio de lo urbano, de lo que sucede en la ciudad. Se concede valor a lo que ahora llamamos técnicas cualitativas de investigación. Comparte una perspectiva hermenéutica de manera que ya no será posible realizar una intervención correcta desde el Trabajo Social sin tener en cuenta el punto de vista del sujeto. Y sin duda, está en el código genético de la profesión, se trabaja en el ámbito de una ciencia con valores. No se pretende simplemente entender la realidad, sino que se trata de entenderla para mejorarla, para cambiarla.

\subsubsection{Pragmatismo}

La filosofía que subyace en los enfoques dominantes de la Escuela de Chicago es el Pragmatismo, concepto de significados variados, pero que hay que precisar porque nada tiene que ver con el desprecio a la teoría ni con una actitud acomodaticia exenta de valores. $\mathrm{Na}$ da más lejos de la realidad. Se trata de una corriente filosófica que nace en EE.UU. y sólo por ello fue vista con displicencia desde la vieja Europa. Por otro lado, no es exactamente lo mismo el Pragmatismo de Pearce que el de W. James o el de J. Dewey. Para entender su significado el historiador Menand recuerda los cambios sucedidos en la sociedad norteamericana y, a la luz de dichos cambios, entender por qué el Pragmatismo les pareció a algunos sectores el utensilio filosófico correcto para algunas décadas después de 1898 . El año en que W. James introdujo el pragmatismo fue también el año «en que la economía americana empezó a alejarse de un ideal individualista de competencia irrestricta para avanzar hacia un ideal burocrático de gestión y regulación» (2002, p. 376). Recuerda Menand que el resultado de la famosa huelga de la Pullman (la compañía que fabricaba lujosos vagones de tren) acabó mal por la cerrazón del propietario, pero que ese resultado dio pie a Dewey y a J. Addams (que había sido elegida como intermediaria por los trabajadores), para afirmar que dicha huelga era el episodio final que demostraba la obsolescencia de las soluciones económicas del siglo XIX. En 1898, el congreso promulgó la Ley Erdman, que reconocía a los trabajadores su derecho a asociarse en organizaciones obreras. El Estado empezó a dejar de ser un invitado de piedra que mira para otro lado e inició un camino más intervencionista. Este es el contexto del periodo de desarrollo del Pragmatismo: el paso del todopoderoso empresario individual a un modelo corporativo más en consonancia con un capitalismo financiero, la aparición de la supervisión de los organismos públicos y la reforma política. Pero ¿qué significado tiene esta corriente pragmática para el Trabajo Social? La respuesta merecería mayores explicaciones, pero Menand nos facilita una respuesta al sintetizar su significado:

No resulta difícil entender el atractivo del pragmatismo en esas circunstancias: todo lo que James y Dewey escribieron como pragmáticos se reduce a una única afirmación: las personas son los agentes de su propio destino. Ellos dispersaron el fatalismo que afecta a casi todos los sistemas de pensamiento del siglo XIX el determinismo mecánico o materialista de autores como Laplace, Malthus, Darwin, Spencer, Huxley y Marx (...). James y Dewey descubrieron un universo aún en progreso, un lugar donde no se desperdicia ninguna conclusión y cada problema puede aceptar el ejerci- 
cio de lo que Dewey denominaba «acción inteligente». Ellos hablaron a una generación de académicos, periodistas, juristas, y diseñadores de políticas ansiosos de encontrar soluciones científicas para los problemas sociales, y felices de recibir buenas razones para ignorar los reclamos de cosmologías finiquitadas (Menand, 2002, p. 377).

Las personas son agentes de su propio destino, no al fatalismo, progreso, soluciones científicas para los problemas sociales... En ese marco conceptual se desarrollaría el trabajo de los chicaguenses y, a través de ellos, llegaría la influencia al Trabajo Social. En la obra y el pensamiento de Jane Addams y de Mary Richmond está sin duda la huella del Pragmatismo que pasaría sin duda a la generación siguiente como se demuestra indubitablemente en la primera página del libro de Gordon Hamilton (1987) principal figura de la Escuela de Nueva York, modelo psicosocial, sucesora y heredera de Richmond: la sociedad está al servicio del individuo y no al revés, cuando una sociedad mejora, el beneficio debe de llegar a todos sus miembros, la educación (clara influencia de Dewey) debe de ser ampliamente promovida, acabando con la referencia a la vieja utopía de la hermandad universal. Como se ve, todo, menos darwinismo o spencerismo (Konopka, 1958; Miranda, 1997).

\subsubsection{Individuo-sociedad}

Me gustaría llamar la atención sobre las conclusiones que Mary Richmond apunta en su obra de madurez, en 1922. Sin ninguna pretensión dogmática, apuntando la posibilidad de que otras bases filosóficas sean descubiertas en el futuro, realiza tres afirmaciones. Primera: los seres humanos son independientes. Y cita a MacIver: «la sociedad mejor ordenada es aquella que desarrolla mejor la personalidad de sus miembros». Se adquiere personalidad teniendo las relaciones necesarias con la sociedad; no se puede adquirir de otra manera. El arte del trabajador social que se consagra al servicio de casos individuales consiste en descubrir las relaciones sociales que más convienen a un individuo y en procurárselas. Segunda: los seres humanos son diferentes los unos de los otros. Un programa social verdaderamente democrático igua- la las posibilidades de todos con una acción inteligente «en conjunto» e instaura al mismo tiempo una política administrativa que trata deferentemente los casos diferentes, y con este fin recurre al concurso de agentes diferentes. Tercera: los seres humanos no son animales domésticos dependientes. Esta diferencia entre el hombre y los otros animales hace necesaria su participación en la elaboración y en la ejecución de planes que tienen a su bienestar. Los individuos poseen una voluntad y finalidades que les son propias, y no están hechos para desempeñar un papel pasivo en la vida: la pasividad los disminuye (1982, p. 171).

En mi opinión esta declaración, a modo de conclusión, no se entiende si no es en términos simultáneamente interaccionistas y pragmatistas. Está utilizando la solución de los interaccionistas para resolver el problema que se venía arrastrando en las Ciencias Sociales relativo a las relaciones entre el individuo y la sociedad (Munné, 1996; Cambiasso et al., 2004). Un problema por cierto fundamental para el Trabajo Social que se debatía entre centrarse en el individuo y para ello debería haber limitado su universo conceptual a lo que proviniera de las disciplinas estudiosas de la mente individual o, por el contrario, focalizar su interés en la dimensión social y acudir en exclusiva a la Sociología, la Antropología, la Economía, el Derecho, la Ciencia Política. Desde la época de las COS en Europa e incluso antes, se arrastraba el gran dilema: ¿cuáles son las causas de la pobreza? ¿Son causas achacables al individuo como la pereza, la vagancia, el consumo de alcohol, la afición por el juego, el desprecio del ahorro, la falta de visión de futuro, una supuesta debilidad moral o mental, la poca responsabilidad respecto a la familia o, por el contrario, son causas sociales que habría que buscar en el sistema económico, en la organización política, en el individualismo calvinista, en la mala distribución de los recursos disponibles, en la ausencia del papel regulador e intervencionista del Estado...? ¿Dónde hay que poner el foco, en el individuo o en la sociedad? ¿Cuál es el tipo de relación entre individuo y sociedad? ¿Cómo influye la sociedad en el proceso de formación de la personalidad del individuo? (Bis- 
no, 1952; Trattner, 1994). El Interaccionismo simbólico supuso ni más ni menos que la solución a estos problemas: no hay mente individual sin grupo social previo. No se puede entender una personalidad individual sin atender al grupo social al que pertenece y, en consecuencia, resulta necesario entender cuál ha sido su historia infantil, escolar, laboral, familiar, económica... Hay que individualizar para conocer a cada sujeto y poder entender lo que significa cada acontecimiento de vida para esa persona en concreto. Cabot también hablaba de esta necesidad imprescindible para una práctica médica de calidad y por ello decidió contar con trabajadoras sociales en su equipo de salud.

A Mary Richmond le costó entender la propuesta interaccionista de que el todo es anterior a la parte y no la parte anterior al todo, pero acabó por asumirla. Todo caso es psicosocial diría años después su alumna, Gordon Hamilton, principal exponente con F. Hollis del modelo así denominado. La herencia de Richmond era importante: una rigurosa propuesta metodológica en el Diagnóstico social, fruto de una concienzuda investigación de miles de casos, la filosofía pragmatista y la solución interaccionista. No hay contradicción sino complementariedad entre una teoría filosófica y otra más cercana a las ciencias sociales. Poco después, en los años 20, llegaría el psicoanálisis y se convirtió sin prescindir de los aportes anteriores, en el paradigma dominante. Buena muestra de ello es también el libro de Hamilton o los de la Escuela de Pennsylvania con el modelo funcional, o el de resolución de problemas de Perlman o el más reciente de intervención en crisis. Fue la propia Mary Richmond la que lanzó a sus colegas a este diálogo permanente con las Ciencias Sociales porque nunca pretendió escribir la obra definitiva o establecer un dogma. Todo no está en Mary Richmond y la que mejor lo sabía era ella misma.

\section{Referencias bibliográficas}

Bisno, H. (1952). The Philosophy of Social Work. Washington: Public Affairs Press.

Butrym, Z.T. (1976). The nature of Social Work. Londres: Macmillan Press.

Cambiasso, N. y Grieco y Bavio, A. (2004). Días Felices. Los usos del orden: de la Escuela de Chicago al Funcionalismo. Buenos Aires: Edit. Eudeba.

Deegan, M.J. (1990). Jane Addams and the Men of the Chicago Scholl, 1892-1918. New Brunswick y Oxford: Transaction Books.

Di Carlo, E. et al. (2005). Trabajo Social y Persona. Mar de Plata: Universidad Nacional de Mar de Plata y Fundación Paideia.

Elshtain, J.B. (2002). Jane Addams and the Dream of American Democracy. Nueva York: Basic Books.

Hamilton, G. (1987). Teoría y práctica. Trabajo Social de casos. México: La Prensa Médica Mexicana.

Hannerz, U. (1993). Exploración de la ciudad. Madrid: FCE.

Jones, M. A. (1995). Historia de Estados Unidos. 1607-1992. Madrid: Edit. Cátedra.

Konopka, G. (1958). Eduard C. Lindeman and Social Work Philosophy. Minneapolis: The University of Minnesota Press.

Leighninger, L. (1987). Social Work. Search for Identity. Nueva York: Greenwood Press.

Menand, L. (2002). El Club de los metafísicos. Historia de las ideas en América. Madrid: Ediciones Destino.

Miller, D.L. (1996). City of the Century. The epic of Chicago and the Making of America. Nueva York: Simond \& Schuster.

Miranda Aranda, M. (1997). M. Richmond y Herbert Spencer y por qué M. Richmond no era darwinista. Trabajo Social y Salud, 27, 11-26.

Miranda Aranda, M. (2004). De la caridad a la ciencia. Pragmatismo, Interaccionismo simbólico y Trabajo Social. Zaragoza: Mira Editores.

Munné, F. (1996). Entre el individuo y la sociedad. Marcos y teorías actuales sobre el comportamiento interpersonal. Barcelona: EUB. 
NASW (1995). Encyclopedia of Social Work. 19a ed. Washington DC: National Association of Social Workers.

Perlman, H.H. (1980). El Trabajo Social individualizado. Madrid. Edic: Rialp

Plummer, K. (edit) (1997). The Chicago School. Londres y Nueva York: Routledge.

Richmond, M. (1982). Caso Social Individual. Buenos Aires: Humanitas.

(2005). Diagnóstico Social. Madrid: Siglo XXI.

Trattner, W.I. (1994).From Poor Law to Welfare State. Nueva York: The Free Press.

Walkowitz, D. (1999). Working with class. Social Workers and the politics of Middle-Class Identity. The University of North Carolina Press. Londres: Chapel Hill. 